\title{
Reaction Soldering with Copper on an Early Medieval Disc Brooch from Germany
}

\author{
Christoph J Raub \\ $\overline{\text { Schuäbisch Gmïnd, Germany }}$
}

\begin{abstract}
Reaction soldering methods were used for making the lavishly decorated Alemannic disc fibula ('Scheibenfibel')* of Lauch heim, to provide a beautiful example of very early goldsmith's work in 'cloisonné' and 'filigree'. The techniques used show superb mastery of the technology of reaction soldering for gold alloys.
\end{abstract}

Pliny the Elder (23-79 AD) in his famous 'Naturalis Historia' told us about the 'soldering' - i.e. really the brazing - of gold (1): 'Chrysokollam et aurifices sibi vindicant adglutimando auro ...' (... Chrysokolla is used by goldsmiths for joining gold ...). Since that time the term 'chrysokolla' has kept linguists, archaeologists, chemists and metallurgists busy since it seems to provide the key to the oldest joining technology used in metal working. Furthermore, it is a fascinating precision method for goldsmiths, which as 'reaction soldering with copper salts' forms the basis for applying geometric gold designs onto gold objects by attaching small granules, wires or strips, of 'granulation' or 'filigree', and generally for soldering or, to be more accurate, for hard soldering or brazing.

The skills and knowledge of this brazing process have been lost several times during its 5,000 years' history. At the beginning of the 20th century this method was patented again (2) and even in modern goldsmith textbooks the principles are often explained inaccurately (3)! On the other hand, the technology is so simple that H. Moesta (4) - a physical chemist, no goldsmith - in his charming booklet on 'kitchen metallurgy' lists a recipe for reaction soldering. This requires only finely ground malachite, a quince or a sour apple, a small piece of gold foil, a block of charcoal, a blow pipe and a small alcohol burning lamp - if necessary, a candle works too - in order to produce classical granulation patterns.

[*] 'Disc fibula' is a term used for a brooch made in the form of a safety pin. The Alemanni tribe lived in Germany in Medieval times.

\section{METALLURGICAL BASIS}

Gold found in nature is in nearly every case a gold-silver alloy with silver contents from fractions of a per cent to more than 20 per cent. At higher silver concentrations the alloys are called electron (Greek) or elertrum (Latin). We do not know how many millennia ago goldsmiths began purposely alloying naturally occurring gold (having less than 1 per cent of copper) to give higher copper concentrations and change the colour into a more pleasing reddish one. This would also require the supply of a standard clean gold - or of refined natural or scrap gold. Thus, alloying and refining would seem to have been connected.

The melting curve for gold-copper alloys does not, however, change continuously, as does the one for gold-silver, but shows a melting point minimum at $889^{\circ} \mathrm{C}$ at a copper concentration of $20 \mathrm{wt} \%$. Such an alloy behaves like a pure metal; it has a sharp melting point, as for a eutectic. Slightly above and below this critical point the alloy is solid, even though the composition is only slightly different. The behaviour is slightly changed by extra alloying elements, e.g., silver, tin or zinc. If 10 per cent copper is added to a binary gold-alloy with 10 per cent silver the melting point drops to $900^{\circ} \mathrm{C}$, and with 30 per cent copper to $850^{\circ} \mathrm{C}$.

The essence of reaction soldering - a term familiar in the trade - is to form a copper-rich zone on the surface of the gold pieces to be joined and keep them in constant contact during warming, e.g. by using an appropriate high-temperature glue or adhesive and finally heating them carefully to a temperature near 
$900^{\circ} \mathrm{C}(5)$. During heating - a goldsmith does it with a blowtorch, today's industry uses furnaces - the copper diffuses into the gold until the critical concentration in the diffusion zone, near 20 per cent, is reached, and it starts to melt at $890^{\circ} \mathrm{C}$, acting as a solder or braze.

The Au-Ag-Cu 20 per cent alloy is rather fluid and due to gravity and surface tension effects fills crevices, cracks or joints, and if the temperature is changed only a little the melt solidifies immediately. Diffusion and melting can be controlled, e.g., via variations in the amount of copper employed, the temperature, and the time of heating, etc. On the other hand, if the joint is heated for a longer time a little below the critical melting temperature, copper diffuses away into the gold, the melting temperature of the joint increases and the joint gets tougher.

These properries enable multiple brazing to be performed successively on one piece. Often overlooked, however, is the fact that when gold alloys with more than one per cent copper are heated in an oxygen-containing atmosphere, they turn black. Consequently, antique objects containing more than one per cent copper, which still look golden, must either have had this tarnished layer of cupric or cuprous oxides removed or possess a gold-enriched surface. Today this depletion gilding (gold enrichment) or 'mise en couleur' of South American Indians, is performed in inorganic acids, usually hot dilute sulphuric acid. In antiquity, either aluminium-based aqueous salt mixtures or organic plant and fruit acids containing rock salt were used. Remains of chlorides and plant acids have been identified in gold enriched surfaces of antique objects (6). The goldenriched zone explains discrepancies in surface investigations of antique objects as well as the 'a priori' minute differences between the solder and the material to be

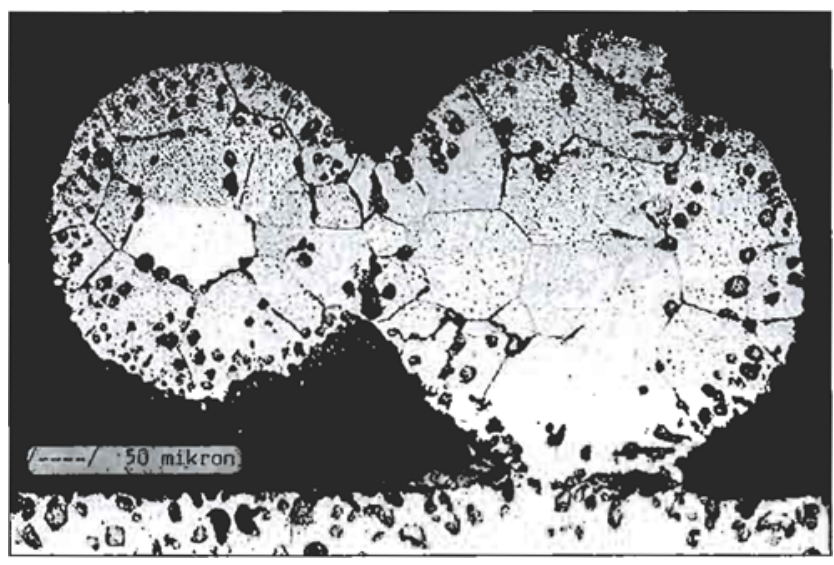

Figure 1 Microsection of a modern granulation alloy: Au-Ag10-Cu15, thermally oxidised. Sample: Raschke, Neg.Nr. 20959 joined $(7,8)$. In antiquity it was possible to produce a copper-enriched zone on the surface of gold in two ways; either by the addition of a copper salt/organics slurry to the joint followed by reduction to metallic copper, or (for gold-silver-copper alloys with more than one per cent copper) by the formation of a layer of copper oxides on top of the gold base by heating in air and subsequent reduction to metallic copper. The second method forms very delicate joints, depending on the process conditions. To the experienced eye, the differences in joints produced by both the methods are just visible due to surface irregularities. These diffusion processes, together with oxidation, produce gold porous zones near the surface which are due to the different diffusion coefficients of gold and copper and its oxidation (Figure I). In addition, it is known that the copper(I) oxide in contact with gold decomposes at higher temperatures into a gold-copper solid solution with the oxygen enhancing copper layer formation (9).

Critical for reaction soldering - and granulation is the selection of a suitable high-temperature 'adhesive' to keep the pieces in place until the formation of the metallic solder begins. Such choices must have resulted in the unbelievable fineness of Hellenistic and Etruscan jewellery. There is a wide range of naturally occurring substances fulfilling such requirements, including gum tragacanth (a sugar or carbohydrate derivate), fish glue, gum arabic and - saliva (9).

If the glue decomposes during heating it can provide additional protection against oxidation as well as producing carbon monoxide for reducing copper oxides to metallic copper. P.M. Roberts described in detail the processes occurring at various temperatures (5).

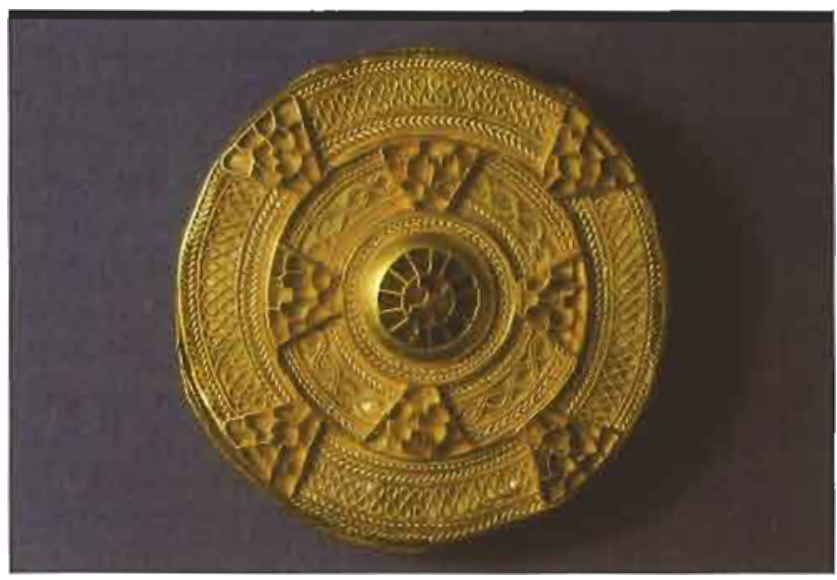

Figure 2 General view of the 'Scheibenfibel' of Lauchbeim Magnification: $c a$ natural size 


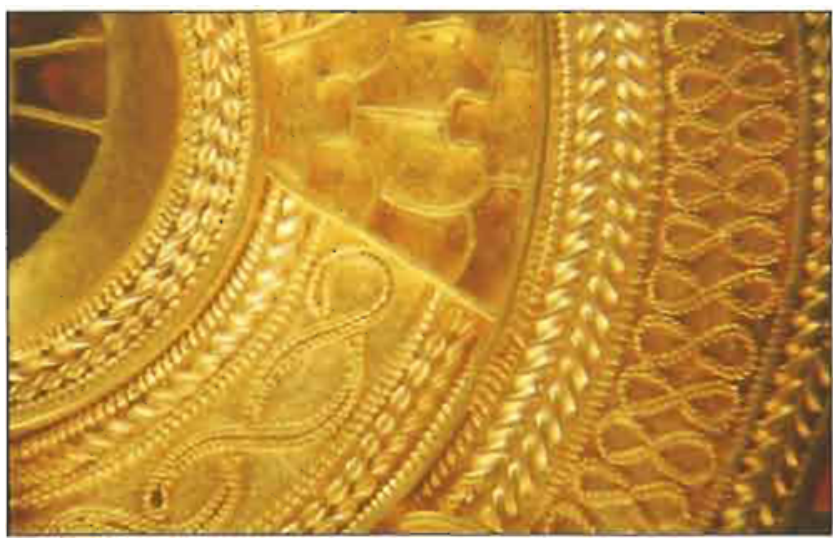

Figure 3 Detail of the cloisonne and filigree work on the Lauch heim fibula; the various decorations were all made with twisted metal wires and strips

Magnification: $c a \times 2$

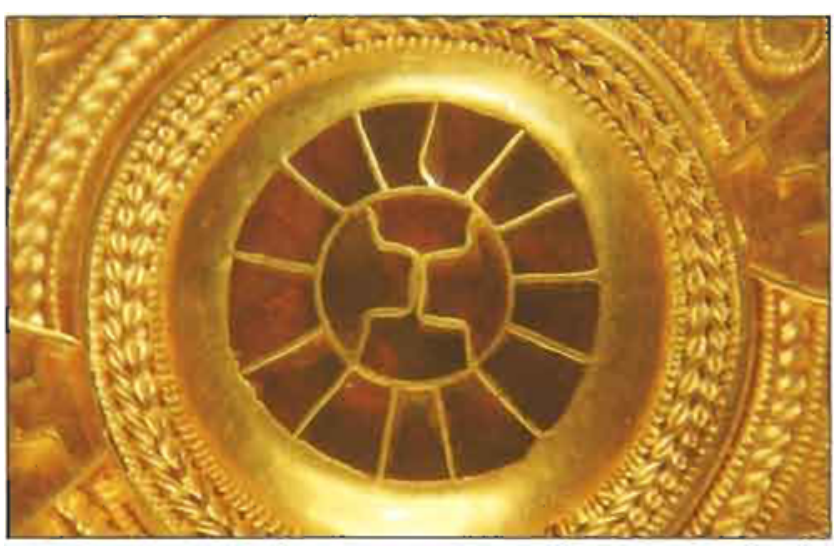

Figure 4 The central dome or 'cloisonne', polished copper-free Au-Ag alloy; inside is the copper oxide film on the base plate, left for decorative purposes to generate the image of almandine or garnets Magnification: $c a \times 2$

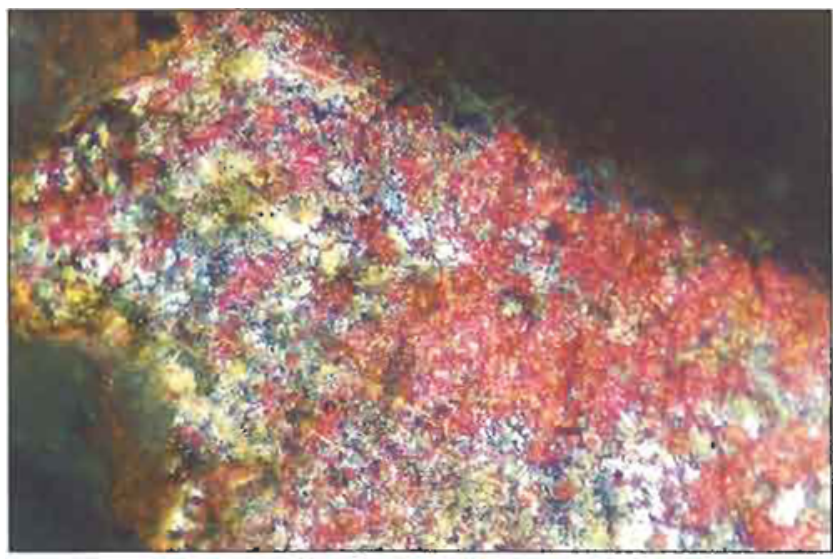

Figure 5 The decorative copper oxide fllm inside the centre 'cloisonné'

Magnification: $c a \times 200$

\section{THE 'SCHEIBENFIBEL' OF LAUCHHEIM}

The disc fibula ('Scheibenfibel') of Lauchheim, Ostalbkreis, Germany, is one of the most lavishly decorated articles ever found in Germany (Figures 2-5). It has been investigated in order to analyse every detail of the methods used in its manufacture, and this enabled the master goldsmiths Morrison and Mallwitz, Align, Germany, to make a replica with the old technique, true to the finest detail.

The fibula is decorated using every variation of gold strips twisted in many different ways. The spiral along the length of the 'block-twisted wire' can be seen only in certain spots since its gaps were filled during soldering. The decoration was soldered onto a thin gold disc which very likely contained some copper. As can be deduced from the rather coarse surface of the soldered plate, soldering was performed via the addition of a slurry of organics and copper compounds (chrysokolla).

The mounted gold plate was itself supported by a thicker disc made from silver/copper alloy (Figure 2). The connecting seam was disguised via use of a beaded gold wire. In general the 'filigree' (wire decoration) and the 'cloisons' (boxes) were made from a gold/silver alloy containing about $10 \%$ silver. Due to the later soldering, leading to contamination of the surface, it is very difficult to decide whether the alloy itself contained copper. However, after mounting, the boxes were all ground down to the same height - this could be done since the central dome was put in last. If the ground edges of the walls of the 'cloison' or the perfectly polished surface of the central 'dome' are analysed, no copper is found. This indicates that the alloy used for decoration, the filigree cloisonné, did not originally contain any copper.

To be more precise, the central dome was made from a copper-free alloy. As a result of its composition the metal neither became tarnished nor lost its polish during its final soldering to the base, which did have a copper oxide layer, enabling reaction soldering! Even in the final 'mise en couleur' or copper oxide leaching operation, all the copper-free alloys remained unchanged.

The final copper oxide leaching was done selectively so that the inside of the dome kept its oxide layer of dark reddish colour (Figure 4). In the corners of some of the cloisonnés where the leaching fluid did not wet the surface, remains of copper oxides can still be found. 
Selective etching can be achieved by protecting with wax and melting the wax out later. Similar observations regarding depletion gilding have been made by the author on Celtic gold coins.

The observations described herein indicate that the residues from thermally-formed copper oxide layers on gold alloys provide important hints for elucidating the methods used for making items of gold jewellery.

\section{CONCLUSIONS}

The alemannic 'Lauchheimer Scheibenfibel' presents a beautiful example of very early goldsmith's work in 'cloisonne' and 'filigree'. It shows superb mastery of the technology of reaction soldering for gold alloys. In addition, surface enrichment of gold by leaching copper oxide was used selectively not only to remove the copper oxide skin but also to leave it in certain areas for decorative purposes*.

\section{ABOUT THE AUTHOR}

Professor Raub retired as Director of FEM last year (see Gold Bulletin 28(1), 1995) and has conducted research on precious metals and their applications for more than 35 years. He is the author of more than 200 publications on modern gold technology and over 70 papers on antique metallurgy.

\section{REFERENCES}

1 'Werkheft Projektgruppe Plinius, (H rsg.), Gold und Vergoldung bei Plinius dem "Älteren" (Work booklet, project group Pliny the Elder, ed.) Attempto Verlag, Tübingen, 1993, p. 27

2 H.P. Littledale, 'A New Process of HardSoldering and its Possible Connection with the Methods used by Ancient Greeks and Etruscans, Lecture IV, Worshipful Company of Goldsmiths, 1936; UK Patent 415, 181; 1934

3 E. Brepohl, 'Theorei und Pravis des Goldschmidts' (Theory and Practice for Goldsmiths), 8. Auflage, VEB Fachverlag, Leipzig, 1987

4 H. Moesta, 'Erze und Metalle' (Ores and Metals), Springer-Verlag, Berlin/Heidelberg/New York, 1983

5 P.M. Roberts, Gold Bull., 1973, 6, 112

6 Ch. J. Raub, unpublished results, and Proc. Metal 95, Seymur en Auxois (1995), in the press

7 C. Eluere, 'Secrets of Ancient Gold', Editions Trio-Guin, Güdlingen, Schweiz, 1989, p.200

8 A.R. Duval, C. Eluere, P. Hurtel and M. Menu, 'Archaeometry', Ed. Y. Maniatis, Elsevier, Amsterdam, 1989, p. 325

9 J. Wolters, Gold Bull., 1981 14, 119

10 K. Alasafi, Ch.J. Raub and E. Raub, Metall., $1982,36,756$

[*] A video on the production of the replica using the old techniques by master goldsmiths Muezzin and Mallwitz, Align, is available from the Landesdenkmalamt Baden-Württemberg (Dr. I. Storck) and the Württembergisches Landesmuseum (Dr. R. Wolf), Stuttgart. 